\title{
The Rhine Outflow Plume Studied by the Analysis of Synthetic Aperture Radar Data and Numerical Simulations
}

\author{
Katrin Hessner* and Angelo Rubino+ \\ Institut für Meereskunde, Universität Hamburg, Hamburg, Germany \\ PETER BRANDT \\ Institut für Meereskunde an der Universität Kiel, Kiel, Germany \\ WERNER ALPERS \\ Institut für Meereskunde, Universität Hamburg, Hamburg, Germany
}

(Manuscript received 16 December 1999, in final form 15 March 2001)

\begin{abstract}
The dynamics of the Rhine outflow plume in the proximity of the river mouth is investigated by using remote sensing data and numerical simulations. The remote sensing data consist of 41 synthetic aperture radar (SAR) images acquired by the First and Second European Remote Sensing satellites ERS-1 and ERS-2 over the outflow region of the river Rhine. Most of them show sea surface signatures of oceanic phenomena, for example, surface current and wind variations, ship wakes, and oil slicks. In particular, in 36 of these images pronounced frontal features are visible as narrow zones of mainly enhanced, sometimes enhanced/reduced radar backscatter that can be associated with the Rhine surface front. Within the area enclosed by the frontal line, large zones characterized by a lower radar backscatter than in the outer area are often visible. The analysis of the ERS SAR images suggests that the form and the location of the frontal features are mainly linked to the semidiurnal tidal phase in the outflow region, although their variability suggests also that they weakly depend on river discharge, residual currents, and neap-spring tidal cycle. In order to test this observational hypothesis, the results obtained from the analysis of the ERS SAR images are compared with the results obtained from the numerical simulation of the hydrodynamics of the Rhine outflow region carried out using a two-layer, frontal model, which is based on the nonlinear, hydrostatic shallow-water equations on an $f$ plane. The model is forced by prescribing tidal and residual currents and river discharge at the open boundaries. Several simulations are performed by varying the values of these forcing parameters. The numerical results corroborate the observational conjecture: It is found that the form and the location of the simulated interface outcropping lines in the proximity of the river mouth are mainly determined by the semidiurnal tidal phase in the outflow region and that river discharge, residual currents, and neap-spring tidal cycle contribute only secondarily to their determination. Inserting the simulated surface velocity field into a simple radar-imaging model that relates the modulation of the backscattered radar power to the surface velocity convergence in radar look direction, narrow, elongated bands of enhanced radar backscatter emerge near the model frontal line while patches of low radar backscatter appear within the simulated Rhine plume area. The consistency of the model results with the results obtained from the analysis of the SAR images enables one to infer a mean spatial and temporal evolution of the Rhine outflow plume over a semidiurnal tidal cycle from the analysis of spaceborne SAR images acquired during different tidal cycles over the Rhine outflow area and suggests the possibility of using numerical modeling, in conjunction with the analysis of spaceborne measurements, for monitoring the oceanic variability in the Rhine outflow area.
\end{abstract}

\section{Introduction}

Oceanic surface fronts can be defined as regions where a maximum in the horizontal gradient of one or

\footnotetext{
* Current affiliation: Ocean Waves GmbH, Lüneburg, Germany.

+ Current affiliation: Dipartimento di Scienze Ambientali dell' Università Ca’ Foscari di Venezia, Venice, Italy.
}

Corresponding author address: Angelo Rubino, Institut für Meereskunde, Universität Hamburg, Troplowitzstr. 7, 22529 Hamburg, Germany.

E-mail: rubino@ifm.uni-hamburg.de more physical, chemical, or biological characteristics of the surface water exists (McClimans 1988). The existence of these surface features, which seem to be ubiquitous in the world ocean, can be caused by a great variety of physical processes like, for example, differential tidal mixing in shelf areas, variability of wind stress, coastal upwelling, or freshwater injections on the top of a heavier ambient ocean (Fedorov 1986).

Different reasons contribute to determine the importance of studying oceanic surface fronts: Often their presence reveals regions where two different water masses meet. Moreover, they can contribute to the deter- 
mination of the ecological equilibrium of large oceanic regions, as they are often linked to an increased concentration of phytoplankton or pollutants (Tyler et al. 1982; Otto et al. 1990).

As oceanic surface fronts can be linked to different phenomena occurring at the sea surface-like, for example, variations in water velocity, salinity, temperature, passive tracers, or color, accumulation of floating debris, or breaking of surface waves-different measurement techniques can be employed for their detection (Joyce 1984; Evans et al. 1985; de Ruijter et al. 1992; Miller et al. 1998). Among them, remote sensing has proved to be a powerful tool for the study of oceanic surface fronts because detecting their signatures synoptically, it can deliver a detailed description of their temporal and spatial evolution often contributing significantly to the understanding of their dynamics achieved using in situ measurement techniques. Perhaps the most widely used remote sensing sensors for the observation of sea surface manifestations of oceanic surface fronts are radiometers and radars (Friede et al. 1991; Johannessen et al. 1991, 1996; Askari et al. 1993; Graber et al. 1996; Vogelzang et al. 1997; Sletten et al. 1999). While using radiometric measurements (radiometers are passive sensors which, in general, are strongly weather-dependent) a classification of different water masses can be achieved by determining their sea surface temperature, their concentrations in phytoplankton, gelbstoff, or suspended matter, radar measurements provide a nearly weather-independent view of the sea surface roughness that depends, among other things, on surface flow divergence and shear and surfactants concentration. Through the analysis of remote sensing data showing sea surface manifestations of oceanic flow features in general, and oceanic surface frontal features in particular, information can be obtained on their spatial and temporal variability that can lead to the formulation of conjectures about different aspects of their dynamical structure. Often the information retrieved from these data can be corroborated by carrying out numerical simulations and/or laboratory experiments. In particular, the numerical simulation of river plumes has a long history. One of the major sources of difficulty in such a task is the numerical treatment of the surface front separating fluvial and marine water. One could thus consider threedimensional primitive equation models as the most adequate tools for the simulation of these fronts. However, a detailed description of the entire complexity of the surface frontal dynamics in a river outflow region is largely inhibited by its often unsustainedly high computational effort (O'Donnell 1993; Esenkov and Cushman-Roisin 1999), as well as by the sensitivity of the obtained solutions to the parametrizations adopted for taking into account turbulent processes (Ruddick et al. 1995). For these reasons, more efficient "process modeling" strategies have been developed in the last three decades, which are still considered among the most valid tools for the description of oceanic flow features in- cluding frontal processes. In this context Garvine (1974a, 1987, 1996) developed different steady-state layered models while, for example, O'Donnell and Garvine (1983), O'Donnell (1990), and McCreary et al. (1997) developed time-dependent layered models, both enabling the assessment of the potential implications of plume fronts on the larger-scale dynamics. The advantage of using these layered models lies in their dynamical simplicity, which allows processes at work in them to be readily diagnosed. At the same time, they are complex enough to permit realistic simulations of several aspects of oceanic phenomena ranging from largescale circulations to small-scale frontal processes (McCreary et al. 1997). Indeed aspects of the dynamics of different mesoscale oceanic frontal features can be also described accurately using even more simplified frontal models that neglect the influence of mixing processes near the surface front on the interior dynamics as they refer to an immiscible (or only weakly miscible) case and simulate surface fronts by simply including techniques for the treatment of movable lateral boundaries (Pavia and Cushman-Roisin 1988, 1990; Sun et al. 1993; Pavia and López 1994; Esenkov and CushmanRoisin 1999; Rubino et al. 2001, hereafter RHB). In the last two decades the number of investigations reporting observations of small-scale surface fronts in coastal areas has dramatically increased. Following O'Donnell (1993), who presented a review of what is known on surface fronts in estuaries, these oceanic features can be classified in three broad (and intersecting) categories, according to the different physical mechanisms responsible for their formation and maintenance: 1) plume and tidal intrusion fronts, 2) tidal mixing fronts, and 3) shear fronts. In particular, plume and tidal intrusion fronts have been widely observed (see, e.g., Wright and Coleman 1971; Garvine 1974b; Stronach 1977; Ingram 1981; Lewis 1984; Luketina and Imberger 1987). These oceanic features mark the boundary between a large, thin surface layer of buoyant water and the heavier, ambient marine water in the proximity of the river mouth, and are generally associated with narrow zones of large horizontal density gradients at the sea surface that may be linked to a strong variation in color, turbidity, or to regions of foam and detritus accumulation. Garvine (1987) and O'Donnell (1990) have distinguished between "large" and "small" plume and tidal intrusion fronts on the basis of the importance of the Coriolis acceleration in the momentum balance near the river outflow (O'Donnell 1993). To this respect, the river Rhine, located in the southern part of the European North Sea, which is the subject of our investigation, presents similarities to the Great Whale and the Connecticut River (O'Donnell 1993). The latter, in particular, has been one of the first locations of the World Ocean where detailed observations of the dynamics of a river plume have been performed. In a series of papers, Garvine (1974a,b, 1977) discovered several general characteristics of the structure and evolution of a river 


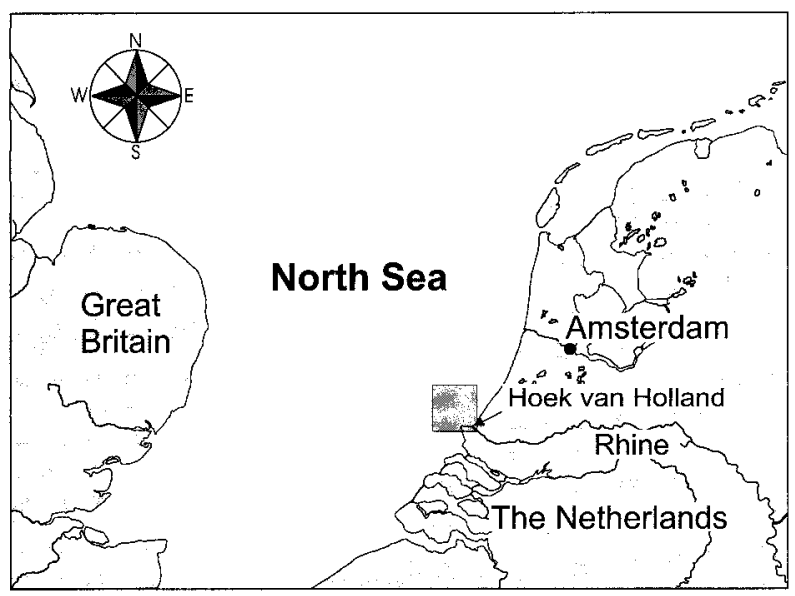

FIG. 1. Geographical map of the southern part of the European North Sea showing the Rhine outflow area. The dark gray area marks the location of the ERS SAR images depicted in Figs. 2, 4, and 5. The arrow marks the position of Hoek van Holland, to which wind speed and direction as well as tidal amplitude and phase refer.

plume subjected to the action of strong tidal currents. Among them is the fact that spatial patterns associated with the river plume are mainly linked to the phase of the tide in the outflow area, and hence repeatable (Garvine 1974a). A similar behavior can be thus expected in the Rhine outflow area (van Alphen et al. 1988). In fact, in this location of the European North Sea (Fig. 1) the presence of an outflow plume, whose surface boundaries are often marked by sharp frontal zones is well documented by in situ as well as remote sensing data (de Loor 1981; van Alphen et al. 1988; de Kok 1997; de Ruijter et al. 1997). Near the Rhine mouth, the interaction of the fluvial currents of the Rhine with the predominantly semidiurnal tide of the North Sea is responsible for the existence of a discontinuous river outflow, which causes a periodic generation of freshwater plumes (van Alphen et al. 1988; van der Giessen et al. 1990; Simpson and Souza 1995; de Ruijter et al. 1997). Their boundaries are usually associated with surface frontal zones that are often visible as narrow, elongated areas of enhanced and/or enhanced/reduced radar backscatter in synthetic aperature radar (SAR) images (Ruddick et al. 1994; Vogelzang et al. 1997).

In this paper we study the dynamics of the Rhine surface front in order to infer characteristics of the dynamics of the Rhine outflow plume. The study is based on an analysis of SAR data acquired by the European Remote Sensing satellites (ERS-1 and ERS-2) over the Rhine outflow area and on an analysis of the results of numerical simulations of the hydrodynamics of the Rhine outflow region carried out with a two-layer frontal model. The analysis of the SAR data consists in the recognition and interpretation of sea surface patterns associated with the Rhine surface front and with other oceanic phenomena like, for example, surface current and wind variations, ship wakes, and oil slicks. The analysis of the results of the numerical simulations, which are performed by using a two-layer frontal numerical model capable of describing the dynamics of a localized layer with an outcropping interface in a dynamically active environment (RHB) consists mainly in the determination of the temporal and spatial evolution of the Rhine surface front for different river discharges, semidiurnal tidal amplitudes, and residual currents. In order to perform such determination, the Rhine surface front is identified by recognizing and interpreting surface patterns obtained by inserting the simulated surface velocity field into a simple radar-imaging model, which relates the modulation of the backscattered radar power to the surface velocity convergence in radar look direction.

The paper is organized as follows: In section 2 the results of our SAR data analysis are presented. In section 3 , using a two-layer frontal numerical model, the Rhine outflow plume dynamics and the surface signatures of the simulated Rhine surface front are studied. Finally, in section 4, in a discussion about possible implications suggested by the analysis of remote sensing data in conjunction with numerical modeling, an attempt is made to infer a mean evolution of the Rhine outflow plume in the Rhine outflow region during a semidiurnal tidal cycle.

\section{ERS SAR images}

\section{a. Radar imaging}

Different oceanic and atmospheric processes that determine the complex structure of the sea surface and its complex interactions with the emitted electromagnetic waves contribute to the radar imaging of oceanic phenomena. This complexity is due to the complexity of the particular oceanic phenomenon considered and of the environmental conditions influencing its dynamics; to the complexity of the surface wave dynamics (in particular surface wave breaking, effects of surfactants); to the complexity of the wind field (local variability induced by the presence of coastal orography, atmospheric fronts, and other small-scale atmospheric features); and to the complexity of the radar imaging of the sea surface (e.g., Bragg scattering versus specular re flection; Brandt et al. 1999).

Among the different theories applied to determine the structure of the sea surface, the wave-current interaction theory has been proved to represent a useful tool in the description of the radar imaging of different oceanic features like, for example, bottom topography in the presence of strong tidal currents (Alpers and Hennings 1984), internal waves (Alpers 1985), or surface fronts (Lyzenga 1991). According to this theory, such features become visible because they are associated with spatially varying surface currents that modulate the sea surface roughness.

Wave-current interaction is a complex mechanism 

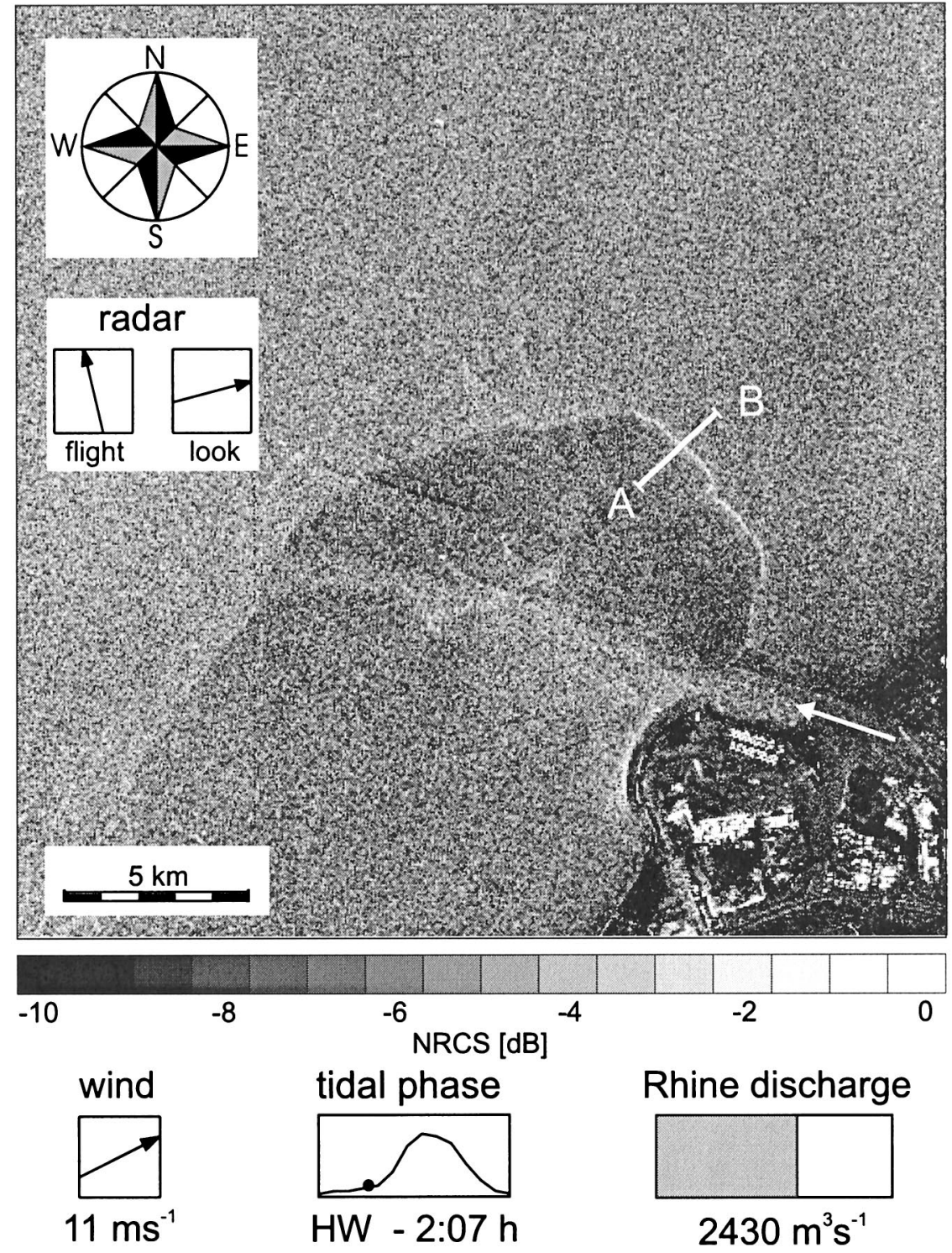

FIG. 2. ERS SAR image acquired at 214613 Oct 1993 over the Rhine outflow area. The white arrow marks the position of the river mouth. The grayscale is proportional to the NRCS. The Rhine surface front is imaged as an almost semicircular line. Along the line AB inserted into this image the variation of the NRCS was determined.

that include the effect of very different physical processes, as, in principle, the full ocean wave spectrum is modulated by a surface current associated with an oceanic phenomenon. This modulation, on its way, results in complex long wave-short wave interactions (see, e.g., Romeiser et al. 1994, 1997a,b). In the presence of oil slicks, additional modulation occurs due to enhanced damping of surface waves induced in regions where these accumulate (see, e.g., da Silva et al. 1998; Ermakov et al. 1998 and references therein). Moreover, foam and detritus at the sea surface (their presence, as well as the presence of oil slicks can be considerable in river outflow areas due to anthropogenic inputs as well as to natural production by biological organisms) can contribute directly to determine the sea surface roughness. Frontal zones characterized by strong surface temperature gradients can separate oceanic regions with different stability in the atmospheric boundary layer above them. The sea surface wind and thus the sea surface roughness will be then stronger/weaker in the oceanic region where the atmospheric boundary layer stability is lower/higher (Keller et al. 1989; Askari et al. 1993). In the following we will assume that wave-current interaction is the dominant mechanism for the radar imaging of surface fronts in river outflow regions. This assumption seems to us the most appropriate one, as far 
as the dynamics of surface fronts in river outflow regions is concerned, as these oceanic features are mainly characterized by areas of strong surface convergence (Garvine and Monk 1974). In the frame of the wave-current interaction theory, the simplest radar-imaging model is that presented by Alpers and Hennings (1984). In this model the relative variation of the normalized radar cross section (NRCS) $\Delta \sigma / \sigma_{0}$ can be related to the horizontal surface velocity as follows:

$$
\frac{\Delta \sigma}{\sigma_{0}} \equiv \frac{\sigma_{f}-\sigma_{0}}{\sigma_{0}}=-A \frac{\partial u_{r}}{\partial x_{r}}
$$

Here, $\sigma_{0}$ denotes the undisturbed NRCS and $\sigma_{f}$ the maximum modulation of the NRCS within the frontal area, while $u_{r}$ denotes the horizontal velocity component along the radar look direction $x_{r}$. In general, $A$ represents a complex function depending, among other things, on radar wavelength, radar incidence angle, and wind speed and direction. In recent years, advanced radar-imaging models for the simulation of synthetic aperture radar signatures of oceanic and atmospheric features over the ocean have been proposed (e.g., Lyzenga and Bennett 1988; Romeiser et al. 1994, 1997a,b). In particular, the model of Romeiser et al. (1997a,b) accounts for contributions of the full ocean wave spectrum to the radar backscatter from the ocean surface including, for example, hydrodynamic long wave-short wave interaction terms accounting thus for the asymmetric distribution of scatterers along intermediate-scale surface waves as well as for upwind/downwind differences of the backscattered signal. Using this model, Brandt et al. (1999) were able to reproduce accurately the modulation of the NRCS associated with an internal solitary wave observed simultaneously by in situ and remote observations in the Strait of Messina. This result was possible because, in that case, the presence of surfactants (whose effect is not included in the advanced radar model) was not important. Moreover, wind speed and direction, on which the simulated modulation of the NRCS crucially depends (Brandt et al. 1999), were known accurately. But, in general, the distribution of surfactants, as well as wind speed and direction, are not known over the ocean with the required accuracy. In this case the results obtained using an advanced radar-imaging model would not be substantially more reliable than those obtained by using a simple radar model (Brandt et al. 1999). On the basis of these arguments we will use in our investigation the simple model described by Eq. (1) in which the function $A$ is constant and positive (Alpers 1985).

\section{b. ERS SAR observations}

In the following we present an analysis of 41 precision-processed ERS SAR images acquired over the Rhine outflow area from 1992 to 1998. This analysis consists in the recognition and interpretation of sea surface patterns visible on the SAR images. For each of

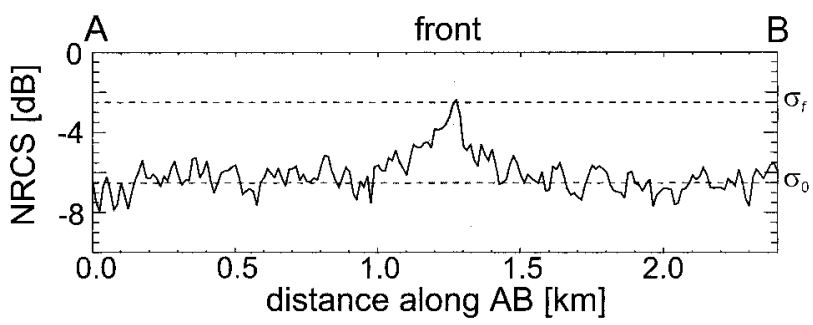

FIG. 3. Profile of the NRCS calculated along the line AB depicts in Fig. 2. The curve represents a mean NRCS obtained by averaging over 40 pixel $(500 \mathrm{~m})$ perpendicular to the line $\mathrm{AB}$. The gray area marks the region of enhanced NRCS corresponding to the Rhine surface front.

the 41 SAR images analyzed, we determined acquisition time, semidiurnal and neap-spring tidal phases, wind speed and direction, and mean water discharge of the Rhine. On these images we could detect roughness patterns referring to different oceanic and atmospheric phenomena that influence the sea surface roughness. Among them, the most common ones refer to surface current and wind variations, ship wakes, and oil slicks. In particular, in 36 images of our dataset, roughness patterns were recognized that can be interpreted as sea surface manifestations of the Rhine surface front, while in 5 images, due to the presence of very strong winds, which induced a sea surface roughness masking the signal produced by the above mentioned phenomena, this was not possible. Our analysis of the ERS SAR images gives no indication that the occurrence of the Rhine surface front varies significantly with season.

An example illustrating typical sea surface patterns visible on SAR images of the Rhine outflow area is shown in Fig. 2. This image was acquired by ERS-1 at 2146 UTC 13 October 1993. The imaged area is $25 \mathrm{~km}$ $\times 25 \mathrm{~km}$. In the lower-right corner of this image part of the Dutch coast including the Rhine mouth (white arrow) is visible. In the center of the image, a sea surface pattern associated with the Rhine surface front can be delineated as a narrow, elongated region (frontal line) enclosing a large surface area in which patches of slightly reduced NRCS (with respect to the outer region) dominate. The frontal line is generally characterized by enhanced NRCS, their maximum values occurring at its northeastern edge. However, we note that the enhancement of the NRCS is smaller in the southern and especially in the western part, where the line seems partly imaged as a zone of enhanced/reduced NRCS.

Figure 3 shows the NRCS profile calculated along the line $\mathbf{A B}$ inserted in Fig. 2. In order to reduce the NRCS variations due to speckle noise, this profile was calculated by averaging the individual NRCS values over 40 pixels $(500 \mathrm{~m}$, as the ERS-1 and -2 SAR pixel size is $12.5 \mathrm{~m}$ ) perpendicular to the line $A B$. In the profile, the sea surface manifestation of the Rhine surface front is visible as a region of enhanced NRCS starting at about $1.2 \mathrm{~km}$ from point $\mathbf{A}$, which has a width 

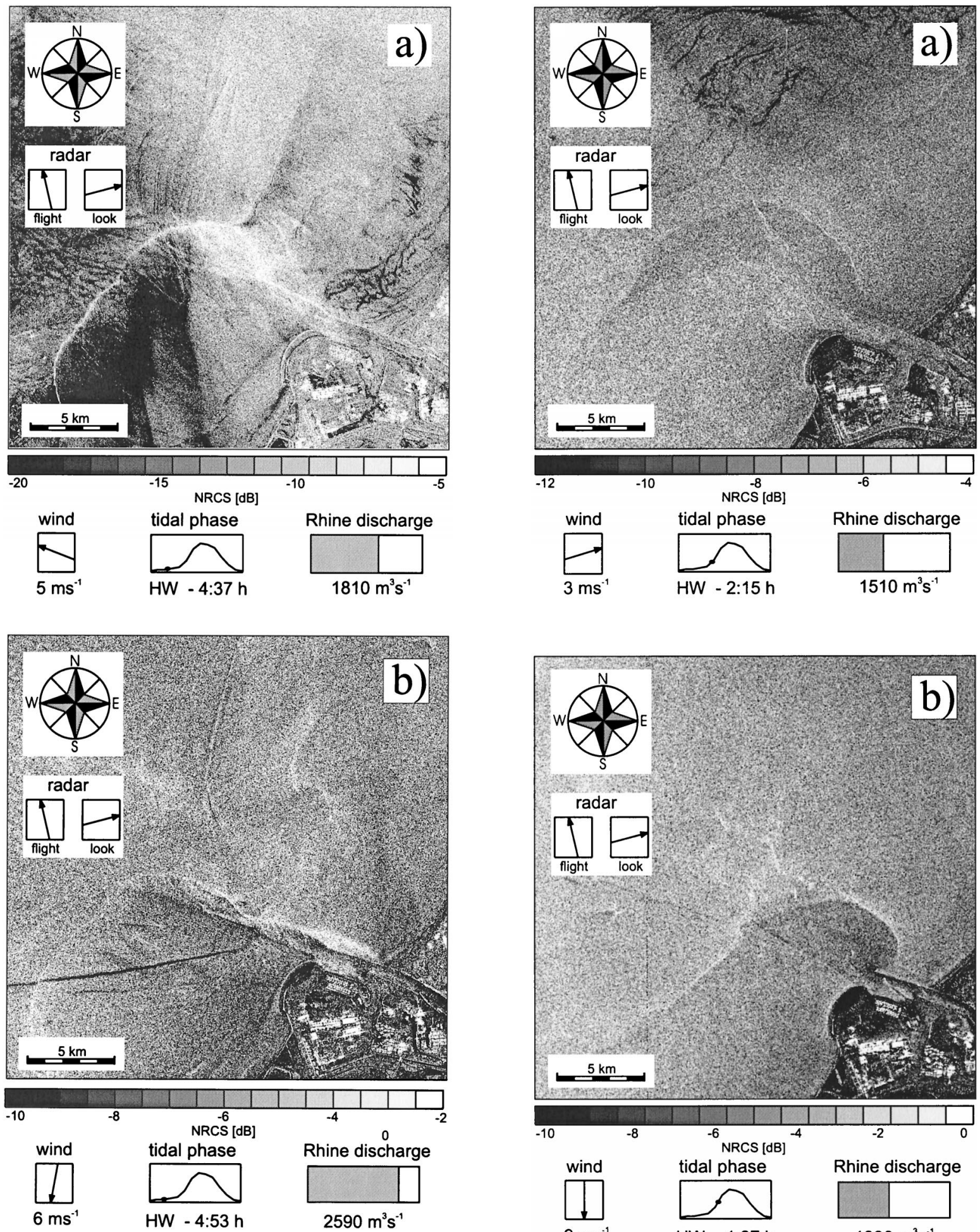

FIG. 4. Two ERS SAR images of the same area as the image depicted in Fig. 2, which were acquired between 4.5 and $5 \mathrm{~h}$ before high water. The SAR image of Fig. 4a was taken at 2146 UTC 15 Jul 1992, the SAR image of Fig. 4b at 2146 UTC 2 Aug 1997. In both images the Rhine surface front is imaged, near the coast, as an almost straight line perpendicular to the coastline, while it is imaged, about $10 \mathrm{~km}$ offshore, as an almost strait line parallel to the coastline.

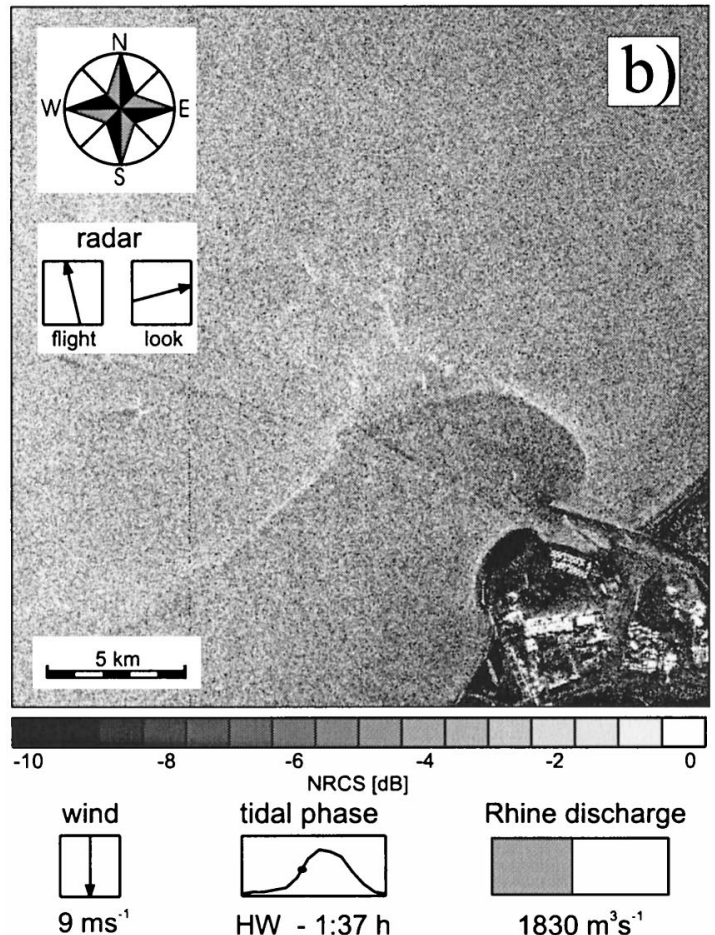

FIG. 5. Two ERS SAR images of the same area as the image depicted in Fig. 2, which were acquired between 1.5 and $2.5 \mathrm{~h}$ before high water. The SAR image of Fig. 5a was taken at 2146 UTC 12 Jul 1996, the SAR image of Fig. 5b at 2146 UTC 30 Mar 1996. In both images the Rhine surface front is imaged as an almost semicircular line (cf. Fig. 2). 
a) Location $A, 6 \mathrm{~km}$ upriver

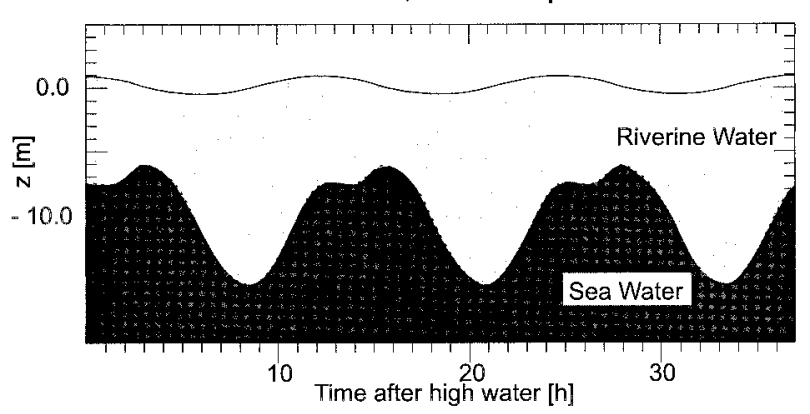

b) Location $B, 7 \mathrm{~km}$ offshore

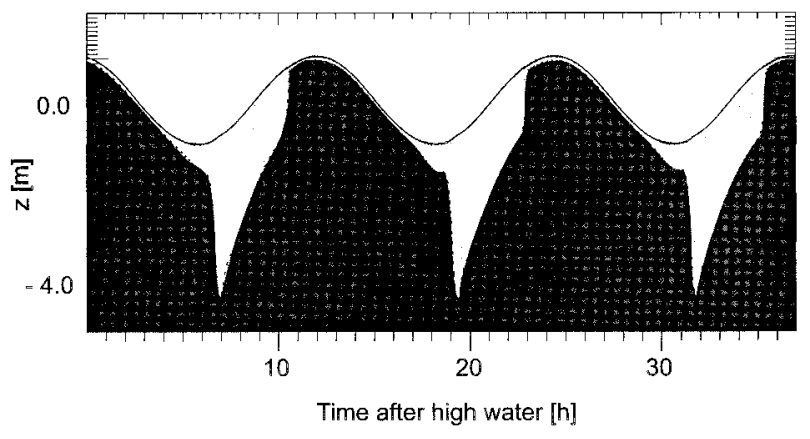

FIG. 6. Time series of the surface and interface displacements at the points A (a) and B (b) (see text) as calculated by our numerical model using typical values of the forcing parameters (see Table 1).

of about $100 \mathrm{~m}$ (Fig. 3, gray area). The relative NRCS variation is approximately $3 \mathrm{~dB}$.

The analysis of the 36 SAR images showing sea surface manifestations of the Rhine surface front yields that, independently of tidal state, wind condition, river discharge, and residual currents, the frontal lines manifest themselves on ERS SAR images as bands dominated by an enhancement of the NRCS. However, in some cases, small portions of the frontal lines are imaged as narrow zones of enhanced/reduced radar backscatter. The observed variability in the structure of the NRCS of the frontal lines may be due to a variable surface convergence or shear near the front (Johannesen et al. 1991), to the variable spatial orientation of the front with respect to the radar look direction and/or to the wind direction (Brandt et al. 1999), and to the presence in the frontal area of natural or anthropogenic surfactants. The large surface areas in which patches of slightly reduced NRCS (with respect to the outer region) dominate could be theoretically interpreted as regions of low wind due to a larger stability of the atmospheric boundary layer above the river plume than above the ambient North Sea water caused by the presence of riverine water colder than ambient water (Askari et al. 1993). However, as the Rhine water is colder than the North Sea water during winter and warmer during summer, a reverse of the above mentioned phenomenon should occur during the year, which is not supported by the analysis of our ERS SAR images.
The form and the location of the radar signatures of the Rhine surface front vary significantly. Among the different processes responsible for the variation of their spatial distribution, semidiurnal tidal currents with their neap-spring modulation, river discharge, and wind-induced currents could be supposed to exert a significant role as a result of our analysis. Their combined effect may explain the large variability observed in the radar signatures of the Rhine surface front. However, from the analysis of our dataset it emerges also that different recurrent radar signatures of the Rhine surface front exist, the most frequent ones being 1) almost straight lines located near the river mouth, 2) nearly semicircular lines located several $\mathrm{km}$ off the coast, and 3) slightly curved lines located farther offshore. The recurrence of these patterns appears to be mainly linked to the semidiurnal tidal phase in the Rhine outflow region.

Figure 4 shows two ERS SAR images from the same area as the image depicted in Fig. 2. Both were acquired during spring tide between 4.5 and $5 \mathrm{~h}$ before high water. Figure 4a was taken at 2146 UTC 15 July 1992 while the wind was blowing from east at about $5 \mathrm{~m} \mathrm{~s}^{-1}$ and the mean river discharge was about $1810 \mathrm{~m}^{3} \mathrm{~s}^{-1}$. Figure 4b was taken at 2146 UTC 2 August 1997 while the wind was blowing from north at about $6 \mathrm{~m} \mathrm{~s}^{-1}$ and the mean river discharge was about $2590 \mathrm{~m}^{3} \mathrm{~s}^{-1}$. Both images show similar form and location of the frontal lines. In spite of the different environmental conditions (e.g., wind direction and water discharge) on both images this line is visible, near the coast, as an almost straight line of enhanced NRCS perpendicular to the coastline, while it is visible, about $10 \mathrm{~km}$ offshore, as an almost straight line of enhanced NRCS parallel to the coastline.

Figure 5 shows two ERS SAR images again of the same area, which were acquired between 1.5 and $2.5 \mathrm{~h}$ before high water. Figure 5a was taken about 5 days before spring tide at 2146 UTC 12 July 1996 while the wind was blowing from west at about $3 \mathrm{~m} \mathrm{~s}^{-1}$ and the mean river discharge was about $1510 \mathrm{~m}^{3} \mathrm{~s}^{-1}$. Figure $5 \mathrm{~b}$ was taken at about spring tide at 2146 UTC 30 March 1996 while the wind was blowing from north at about $9 \mathrm{~m} \mathrm{~s}^{-1}$ and the mean river discharge was about 1830 $\mathrm{m}^{3} \mathrm{~s}^{-1}$. Both images show similar form and location of the frontal lines. Also in this case, in spite of the different environmental conditions (e.g., wind speed and direction, neap-spring tidal phase, and water discharge) in both images these lines are visible as almost semicircular lines. In particular, in Fig. 5b the frontal line encloses a region where large zones characterized by a lower NRCS than in the outer surrounding area can be observed. In Fig. 5a this phenomenon is less evident. Still, especially near the northern edge of the frontal line, a contrast between the NRCS values within and outside the plume can be observed. In the five images presented above and, in general, in the whole set of ERS SAR images, additionally to the frontal lines associated with the Rhine plume, several other phenomena can be detected. Note, however, that their interpretation is often 

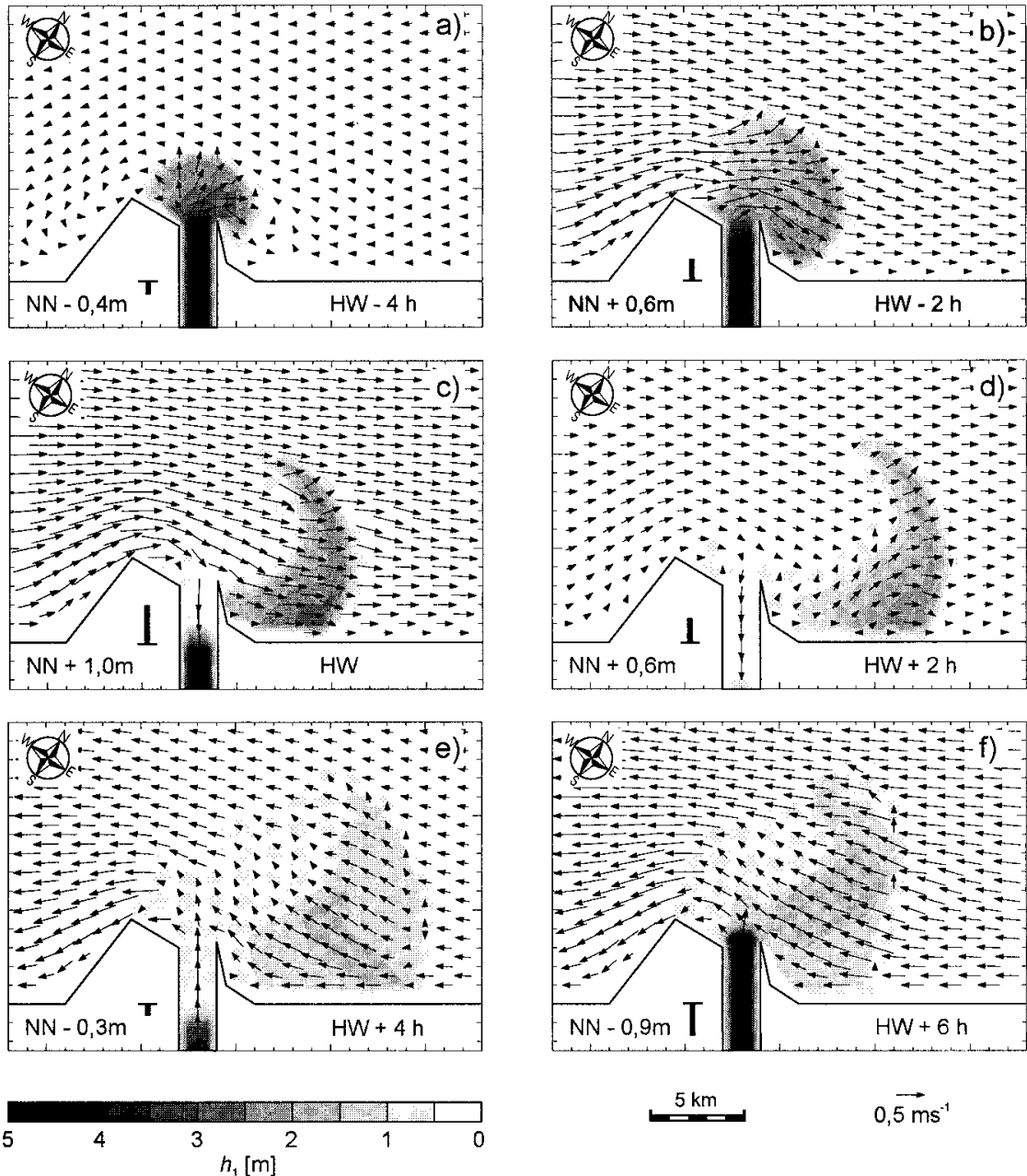

FIG. 7. Rhine plume thickness and horizontal surface velocity field of the composite plumeambient sea system as calculated by our numerical model using typical values of the forcing parameters (see Table 1) for six selected times. The symbol NN indicates the mean sea level.

uncertain and remains obscure if further information is not provided. The difficulty in distinguishing these different surface patterns from the Rhine plume front may be at least partly overcome by intercomparing different remote sensing or in situ data and/or by interpreting these surface patterns with the help of numerical simulations aimed at describing the gross characteristics of the Rhine outflow plume.

\section{Numerical simulation of the Rhine outflow plume and of the radar signatures of the Rhine surface front}

In the present section we carry out numerical simulations of the hydrodynamics of the Rhine outflow region area in order to produce surface frontal features associated with the Rhine outflow plume. Using the simple radar-imaging model described in section 2 the simulated surface velocity field is used to obtain theoretical radar signatures of the Rhine outflow front. The numerical model used in our study is a frontal two-layer model. Its details and the model setup are given in the appendix. Obviously, using such a simplified numerical model it is not possible to address the whole complexity characterizing the hydrodynamics of a region of freshwater influence like the Rhine outflow area, but it is nevertheless possible to elucidate aspects of the evolution of the Rhine surface front near the river mouth.

\section{a. Hydrodynamics of the Rhine outflow for typical values of the forcing parameters}

The model response to typical values of the river discharge $Q$, of the amplitude of the semidiurnal tide $U_{T 0}$, and of the tidal residual transport $U_{R}$, (see Table 1) is illustrated in Figs. 6 and 7. In Fig. 6 time series of the surface and interface displacements at a point located upriver approximately $6 \mathrm{~km}$ far from the mouth 


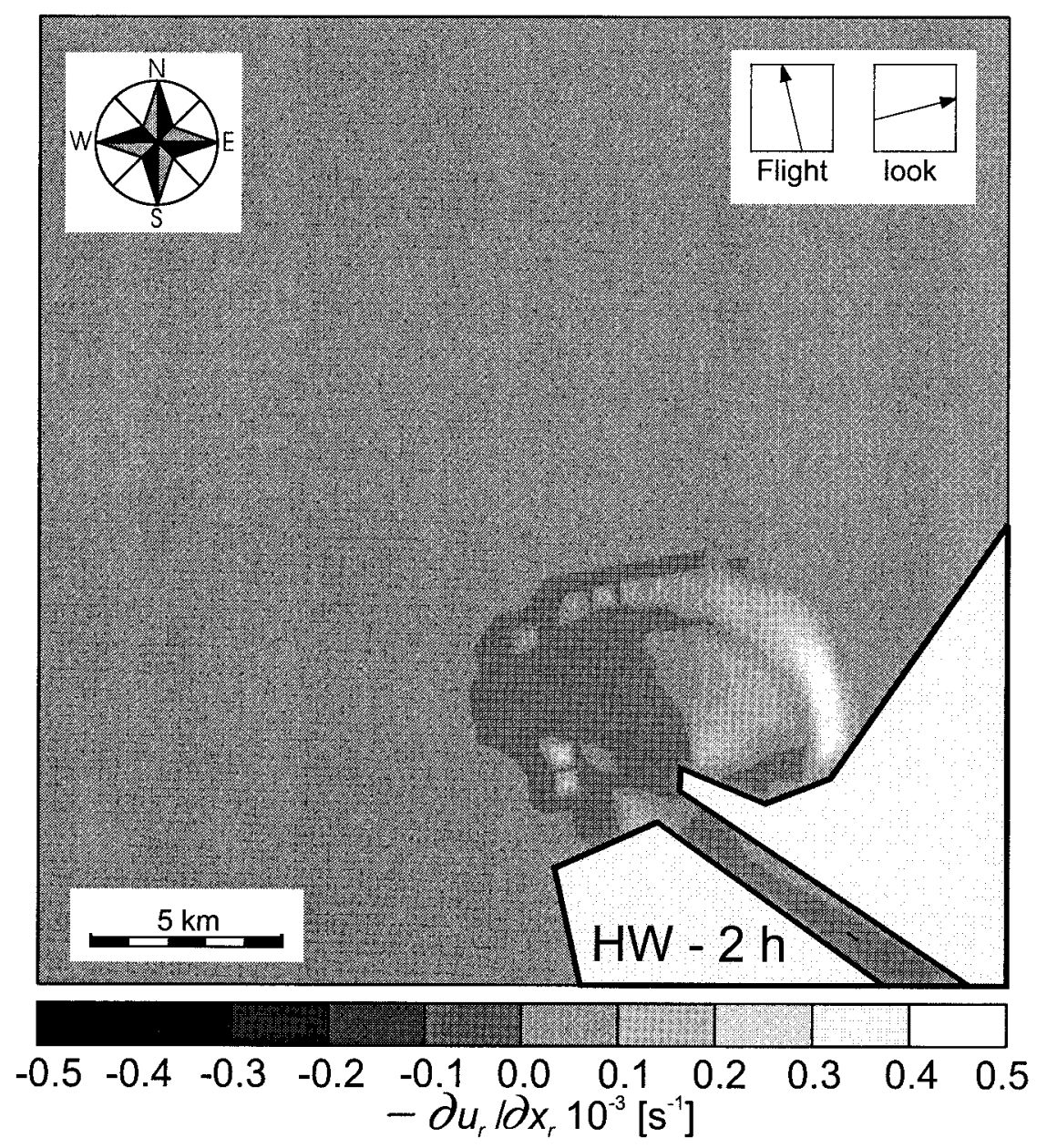

FIG. 8. Surface velocity convergence in the direction coinciding with the radar look direction of the SAR images shown in Figs. 2, 4, and 5 as calculated by our numerical model using typical values of the forcing parameters (see Table 1) for high water minus two hours (see Fig. 7b).

(Fig. 6a) and at a point located approximately $7 \mathrm{~km}$ offshore the river mouth (Fig. 6b) are presented. In the following we will refer to these points as to point $\mathrm{A}$ and point $\mathrm{B}$, respectively. Their positions are also marked in Fig. A2 of the appendix. From this response it is evident that an almost periodic pulsation of the river outflow exists. At point A the water column is stratified throughout the tidal cycle. The thickness of the upper layer is maximum shortly after low water and minimum shortly after high water. On the contrary, the time series calculated at the point B shows that the water column is not stratified throughout the whole tidal cycle. The Rhine plume reaches this point about $4 \mathrm{~h}$ after high water, thus giving rise to a stratified water column, which lasts about $6 \mathrm{~h}$.

The Rhine plume thickness and the horizontal surface velocity field of the composite plume-ambient sea system as calculated by the numerical model for six selected times of a tidal cycle are presented in Fig. 7. Due to the joint effect of tidal current advection and Coriolis force the plume is shifted to the right of the river mouth.
In general, if one excludes the upriver region, the largest plumes thicknesses are encountered near the coast, northeastward of the river mouth.

\section{b. Simulated radar signatures of the Rhine outflow front for different forcing parameters}

Figure 8 shows the surface velocity convergence in the direction coinciding with the radar look direction of the SAR images depicted in Figs. 2, 4, and 5 as simulated by our numerical model for high water minus 2 h. The northeastern edge of the simulated Rhine plume is linked to a narrow band of enhanced surface velocity convergence which, according to the radar-imaging theory used in our investigation [Eq. (1)], results in a narrow band of enhanced NRCS in a theoretical radar image. Note that such band is located near the model frontal line (see Figs. 7b and 8). The proximity of these two regions is a characteristic that we observed in all numerical simulations carried out using our numerical model. In a large portion of the plume area, which is 

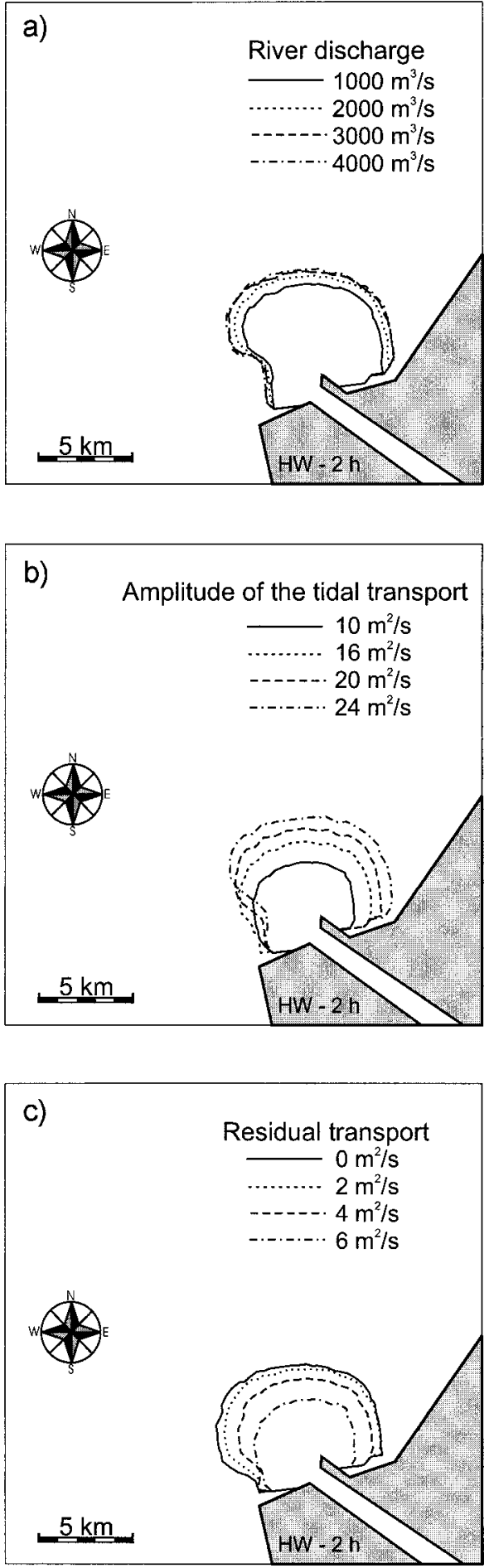

FIG. 9. Form and location of the Rhine surface front for four different river discharges (a), four different amplitudes of the semidiurnal tidal transport (b), and four different residual transports (c). In the three sets of simulations we varied the value of one forcing parameter, while the remaining two forcing parameters were assumed to be constant. Their values are $U_{T 0}=24 \mathrm{~m}^{2} \mathrm{~s}^{-1}$ and $U_{R}=5 \mathrm{~m}^{2} \mathrm{~s}^{-1}$ (a), $Q=2500 \mathrm{~m}^{3} \mathrm{~s}^{-1}$ and $U_{R}=5 \mathrm{~m}^{2} \mathrm{~s}^{-1}$ (b), and $Q=2500 \mathrm{~m}^{3} \mathrm{~s}^{-1}$ and $U_{T 0}=16 \mathrm{~m}^{2} \mathrm{~s}^{-1}(\mathrm{c})$. The curves refer always to high water minus $2 \mathrm{~h}$. enclosed by the Rhine surface front, the surface velocity field is slightly divergent, which according to Eq. (1), yields a region of reduced NRCS in a theoretical radar image.

In order to elucidate the dependence of the form and of the location of the Rhine surface front on river discharge, amplitude of the semidiurnal tidal transport, and residual transport, we performed several numerical simulations by varying the values of these forcing parameters. In Fig. 9 three sets of curves are shown, which represent the Rhine surface front as simulated by our numerical model for high water minus $2 \mathrm{~h}$. The curves calculated for four different river discharges (Fig. 9a), for four different tidal amplitudes (Fig. 9b), and for four different residual transports (Fig. 9c) indicate that, in the region near the river mouth, the form and the location of the Rhine surface front do not strongly depend on these forcing parameters. This result appears to be also independent on the phase of the semidiurnal tide. In particular we note that, for large values of the water discharged by the Rhine into the North Sea, the surface area of the plume does not increase appreciably by increasing discharge (Fig. 9a). This result is in good agreement with previous observations carried out in the Connecticut River outflow area, which suggest a deepening of the river plume at the expense of its area at high discharge levels (Garvine 1974b).

\section{Discussion}

In this paper a study on the dynamics of the Rhine outflow plume in the proximity of the river mouth was presented. The study is based on the analysis of $41 \mathrm{SAR}$ images acquired over the Rhine outflow region and on numerical simulations carried out by using a two-layer frontal numerical model. From the analysis of the SAR data it could be conjectured that the form and the location of the Rhine surface front mainly depend on the phase of the semidiurnal tide in the outflow area. In order to test the validity of this observational hypothesis, we implemented a numerical model, which, due to a special technique for the treatment of movable lateral boundaries, is capable of describing the temporal and spatial evolution of a localized layer with an outcropping interface in a dynamically active environment. Using this model, which obviously is not intended for addressing the whole complexity connected to a realistic description of a region of freshwater influence, we could concentrate on the recognition and the interpretation of specific surface patterns that emerge in this area when the simulated convergence field is inserted into a simple radar model. In particular, using this approach we were able to produce sea surface patterns resembling patterns observed on ERS SAR images of the Rhine outflow area: 1) narrow zones characterized by an enhanced surface velocity convergence in radar look direction associated with the Rhine plume front, and 2) large patches of weak surface velocity divergence within the plume 


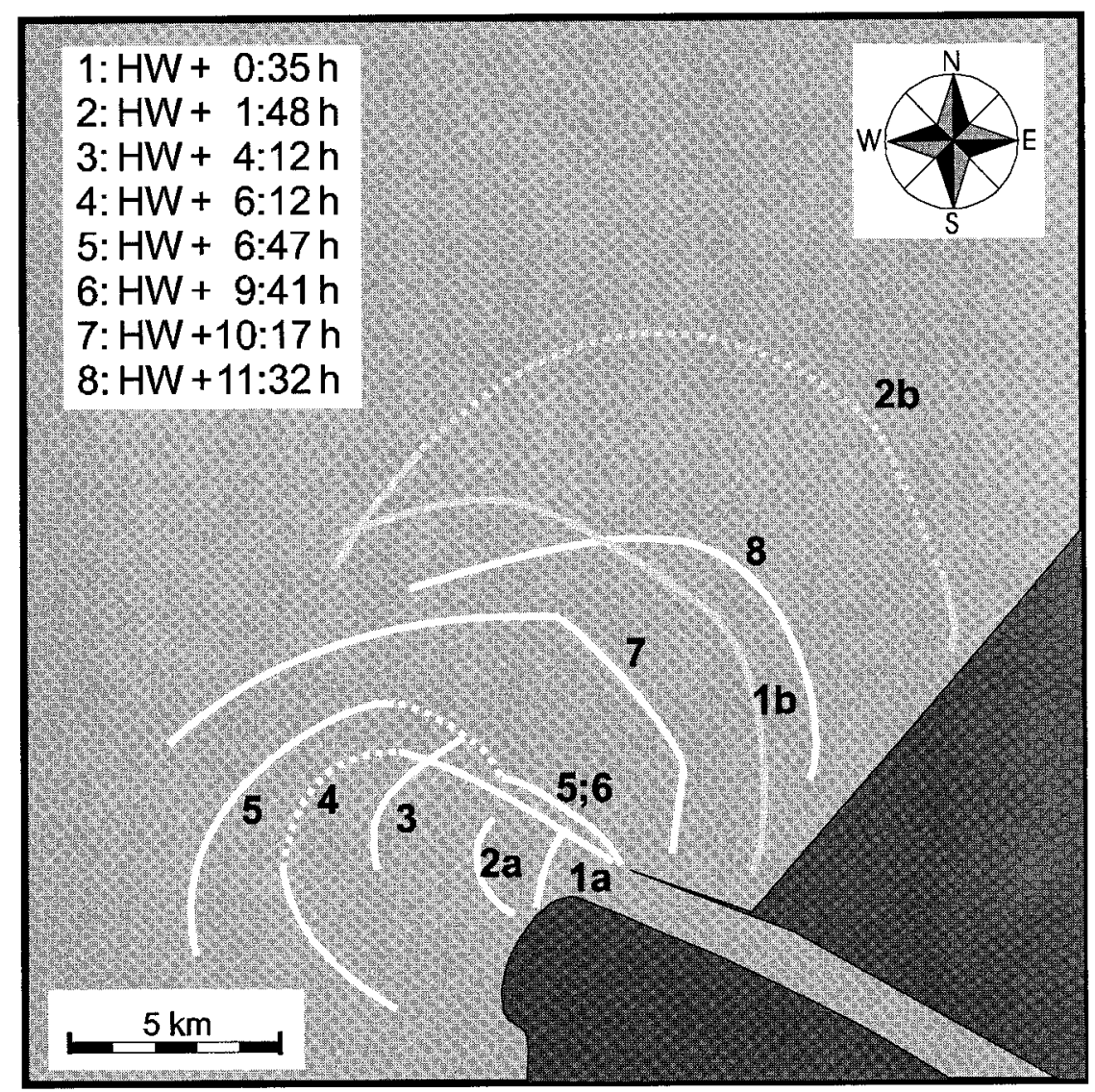

FIG. 10. Schematic plot of the form and of the location of the Rhine surface front as inferred from eight ERS SAR images acquired during different phases of different tidal cycles. The white lines refer to the surface manifestations of the Rhine surface front, which can be associated with the evolution of the Rhine plume within a single semidiurnal tidal cycle. The gray lines refer to the surface manifestations of the Rhine surface front, which can be associated with the evolution of the Rhine plume generated during the previous tidal cycle.

area. The latter result indicates that the presence of similar dark patches visible on ERS SAR images is due to the specific dynamics of the Rhine plume rather than to variations in the air-sea temperature differences between plume and ambient sea.

Our sensitivity experiments indicate that, as suggested by the analysis of the SAR data, the form and the location of the Rhine surface front are mainly linked to the phase of the semidiurnal tidal cycle in the outflow region and that they only weakly depend on river discharge, residual currents, and neap-spring tidal cycle. This situation is typical of the behavior of a river plume subjected to strong tidal forcing, firstly investigated in

TABLE 1. Typical values of the forcing parameters used in the numerical simulations.

\begin{tabular}{lll}
\hline \hline River discharge & $Q$ & $2000 \mathrm{~m}^{3} \mathrm{~s}^{-1}$ \\
Amplitude of the tidal transport & $U_{T O}$ & $24 \mathrm{~m}^{2} \mathrm{~s}^{-1}$ \\
Residual transport & $U_{R}$ & $1.0 \mathrm{~m}^{2} \mathrm{~s}^{-1}$ \\
\hline
\end{tabular}

detail in the Connecticut River outflow area (Garvine 1974b).

On this basis an attempt can be made to infer, from SAR images showing sea surface manifestations of the Rhine surface front, which were acquired during different tidal cycles over the Rhine outflow area, a mean spatial and temporal evolution of the Rhine outflow plume. Figure 10 schematizes the form and the location of the Rhine surface front as inferred from eight ERS SAR images acquired during different phases of different tidal cycles. Shortly after high water the Rhine outflow gradually starts and a buoyant plume begins to develop. At this time the tidal current is about maximum and is directed northeastward, along the coast. At the Rhine mouth a nearly straight front is visible which is aligned with the direction of the tidal current (line 1a). About $8 \mathrm{~km}$ northeast of the river mouth a second front is visible (line 1b), which is associated with the plume generated during the previous tidal cycle. About $2 \mathrm{~h}$ after high water the front located in the vicinity of the 
river mouth has moved about $1 \mathrm{~km}$ offshore and its curvature has increased (line $2 \mathrm{a}$ ). The front associated with the plume generated during the previous tidal cycle has moved northeastward, advected by the tidal current, and is now located approximately $12 \mathrm{~km}$ off the Rhine mouth (line $2 \mathrm{~b}$ ). About $4 \mathrm{~h}$ after high water, the tidal current turns from northeast to southwest. The buoyant plume has spread farther offshore. Its front is now located about $4 \mathrm{~km}$ off the river mouth (line 3 ). Around low water the outflow at the river mouth is about maximum. The front is now visible as an almost semicircular line located in the vicinity of the river mouth (line 4). Note that a northeastward spreading of the buoyant plume is now inhibited by the presence of a southwestward tidal current. About half an hour after low water the buoyant plume has spread farther offshore. At this time only its northwestern and coastal edges are visible as frontal lines (line 5). About $3 \mathrm{~h}$ after low water, only the part of the front located near the New Waterway quay is visible (line 6). Note that the form and the location of this portion of the Rhine surface front have not changed substantially during the previous $3 \mathrm{~h}$. About $2 \mathrm{~h}$ before high water, the tidal current turns again northeastward. Now the riverine water is free to spread northeastward and the front is visible as a nearly semicircular line (line 7). About one hour before high water, the front has moved farther northeastward, advected by the northeastward tidal current (line 8).

Acknowledgments. This study has been funded by the Deutsche Agentur für Raumfahrtangelegenheiten (DARA) under Contract 50EE9413. The ERS SAR data were supplied within the framework of Pilot Project A02.D108. We thank J. de Kok from Rijkswaterstaat, Netherlands, for providing the wind data.

\section{APPENDIX}

\section{Numerical Model and Model Setup}

\section{a. Numerical model}

The model that we employ for describing the Rhine outflow dynamics is a two-layer frontal model as schematically depicted in Fig. A1. In this figure, $D$ denotes the water depth; $h_{1}$ and $h_{2}$ the thicknesses of the upper and lower layer, respectively; and $\eta_{1}$ and $\eta_{2}$ the surface and interface displacements relative to the mean sea surface, respectively. The equations that constitute our model are the nonlinear, hydrostatic, shallow-water equations for a two-layer system on an $f$ plane. They include horizontal momentum diffusion as well as vertical shear stress terms at the bottom and at the interface between the two water layers. In the following we denote the vertically averaged velocity and transport vectors by $\mathbf{u}_{i}$ and $\mathbf{U}_{i}=\mathbf{u}_{i} h_{i}$, respectively. The subscripts $i$ $=1$ and $i=2$ refer to the upper and lower layer, respectively. For the upper layer, the momentum and the continuity equations read

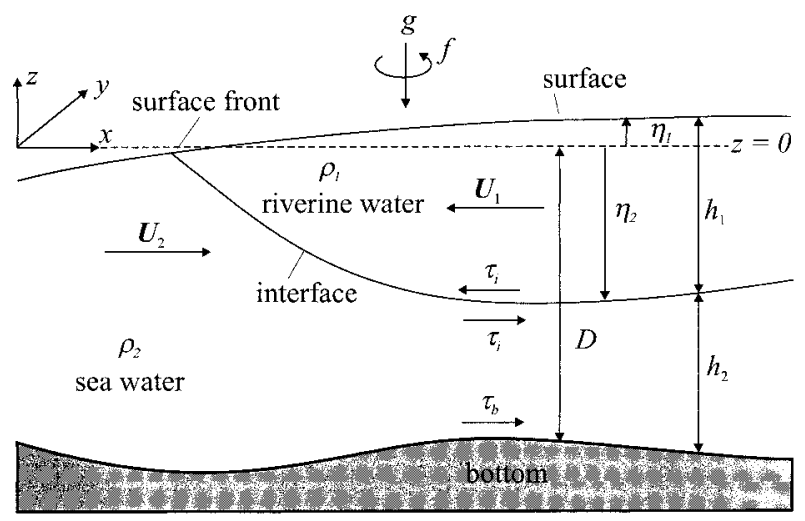

FIG. A1. Schematic plot illustrating the two-layer frontal model. Here $D$ represents the mean water depth; $h_{1}$ and $h_{2}$ the thicknesses of the upper and lower layer, respectively; and $\eta_{1}$ and $\eta_{2}$ the surface and interface displacements relative to the mean sea surface, respectively. The transports in the upper and lower layer, whose densities are $\rho_{1}$ and $\rho_{2}$ denoted by $\mathbf{U}_{1}$ and $\mathbf{U}_{2}$, respectively. The vertical shear stresses at the interface and at the bottom are denoted by $\boldsymbol{\tau}_{i}$ and $\boldsymbol{\tau}_{b}$, respectively.

$$
\begin{aligned}
\frac{\partial \mathbf{U}_{1}}{\partial t}+\boldsymbol{\nabla}_{h} \cdot\left(\mathbf{u}_{1} \times \mathbf{U}_{1}\right)+\mathbf{F}_{h} \cdot \mathbf{U}_{1}= & -g h_{1} \nabla_{h} \eta_{1}-\frac{\boldsymbol{\tau}_{i}}{\bar{\rho}} \\
& +A_{h} \nabla_{h}^{2} \mathbf{U}_{1} \\
\frac{\partial h_{1}}{\partial t}+\nabla_{h} \cdot \mathbf{U}_{1}= & 0
\end{aligned}
$$

while for the lower layer they read

$$
\begin{aligned}
\frac{\partial \mathbf{U}_{2}}{\partial t}+ & \nabla_{h} \cdot\left(\mathbf{u}_{2} \times \mathbf{U}_{2}\right)+\mathbf{F}_{h} \cdot \mathbf{U}_{2} \\
= & -\frac{\rho_{1}}{\bar{\rho}} g h_{2} \nabla_{h} \eta_{1}-g^{\prime} h_{2} \nabla_{h} \eta_{2}+\frac{\boldsymbol{\tau}_{i}}{\bar{\rho}} \\
& -\frac{\boldsymbol{\tau}_{b}}{\bar{\rho}}+A_{h} \nabla_{h}^{2} \mathbf{U}_{2},
\end{aligned}
$$

$\frac{\partial h_{2}}{\partial t}+\nabla_{h} \cdot \mathbf{U}_{2}=0$.

Here $\nabla_{h}$ denotes the horizontal Nabla operator, $\cdot$ the scalar product, and $\times$ the tensor product. The two-dimensional Coriolis matrix $\mathbf{F}_{h}$ is defined as

$$
\mathbf{F}_{h}=\left(\begin{array}{cc}
0 & -f \\
f & 0
\end{array}\right),
$$

where $f$ is the Coriolis parameter. The water densities in the upper and lower layer are $\rho_{1}$ and $\rho_{2}$, respectively; $\bar{\rho}=\left(\rho_{2}+\rho_{1}\right) / 2$ is the mean water density; $g^{\prime}=g\left(\rho_{2}\right.$ $\left.-\rho_{1}\right) / \bar{\rho}$ is the reduced gravity, where $g$ denotes the acceleration of gravity; and $A_{h}$ is the horizontal eddy diffusion coefficient. The vertical shear stresses at the interface, $\boldsymbol{\tau}_{i}$, and at the bottom, $\boldsymbol{\tau}_{b}$, are assumed to de- 


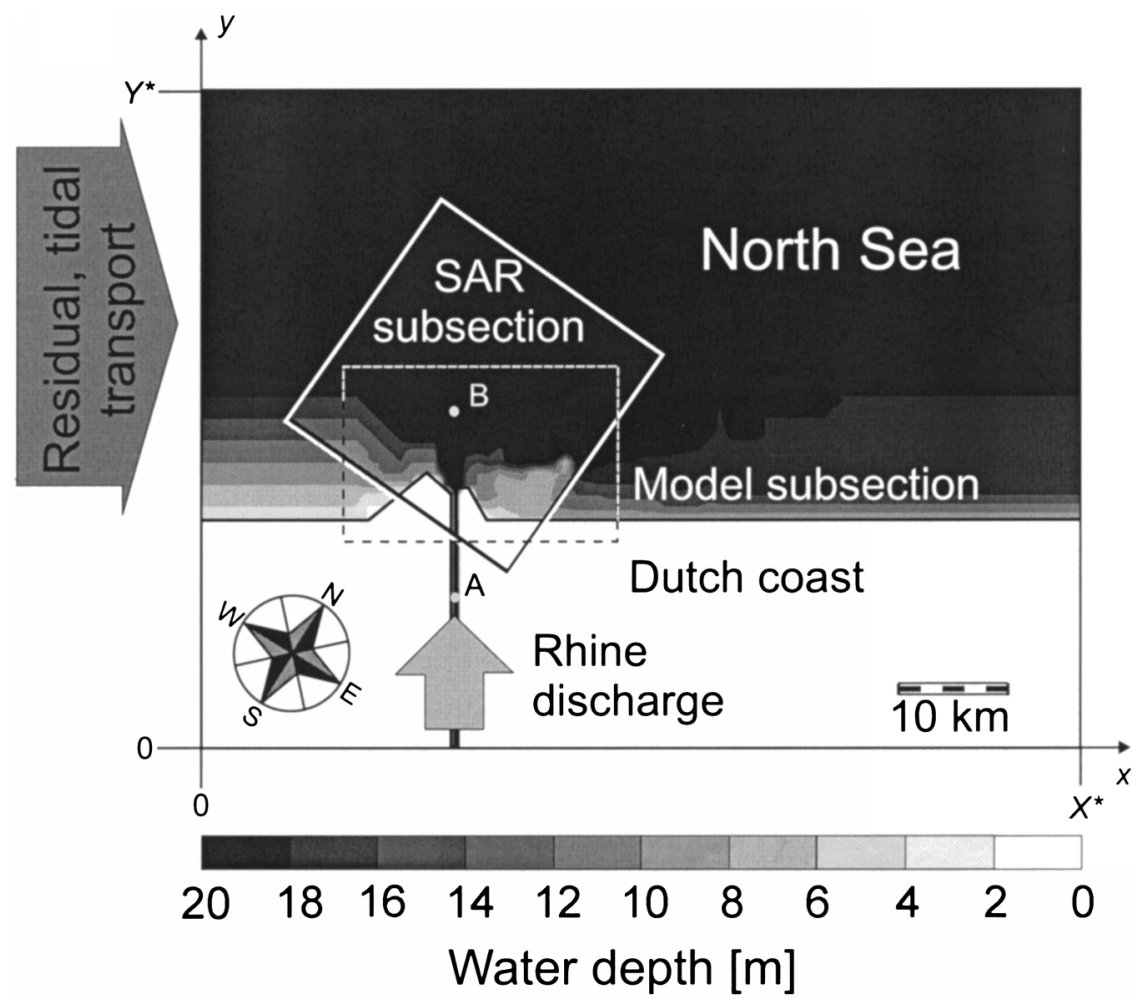

FIG. A2. Bathymetry used in the numerical simulations. The solid-line square marks the area of the SAR images depicted in Figs. 2, 4, and 5. The dashed-line rectangle as well as the points $\mathrm{A}$ and $\mathrm{B}$, marks location to which model results refer.

pend on the current velocity in the upper and lower layers in the following way:

$$
\begin{aligned}
& \frac{\boldsymbol{\tau}_{i}}{\bar{\rho}}=c_{d i}\left(\mathbf{u}_{1}-\mathbf{u}_{2}\right)\left|\mathbf{u}_{1}-\mathbf{u}_{2}\right|, \\
& \frac{\boldsymbol{\tau}_{b}}{\bar{\rho}}=c_{d b} \mathbf{u}_{2}\left|\mathbf{u}_{2}\right|,
\end{aligned}
$$

where $c_{d i}$ and $c_{d b}$ denote the nondimensional drag coefficients at the interface and at the bottom, respectively. Note that in our model the densities $\rho_{1}$ and $\rho_{2}$, as well as the coefficients $A_{h}, c_{d i}$, and $c_{d b}$ are assumed to be constant.

The equations are discretized on a staggered Arakawa $\mathrm{C}$ grid. The numerical scheme for the integration of the Eqs. (A1)-(A4) uses forward differences in time and central differences in space. The advective terms are solved by means of a directional upstream algorithm. The model is a frontal model. In fact in this model a special technique for the numerical treatment of movable lateral boundaries allows for the description of the temporal and spatial evolution of a localized layer with an outcropping interface in a dynamically active environment. For further details about this numerical technique and about the numerical tests (which were performed by comparing nonstationary analytical solutions of the nonlinear reduced-gravity shallow-water equa- tions on an $f$ plane that describe frontal surface vortices with the results obtained numerically) used to validate the numerical model the reader is referred to RHB. The model results, due particularly to the absence, in our formulation, of parameterizations describing frontal mixing processes, and due to a limited spatial resolution $(500 \mathrm{~m})$, cannot provide quantitative information on surface convergence near the river Rhine front. However, our goal is to show that the numerical results are in good qualitative agreement with observations, especially as far as the variability of the form and the location of the surface front is concerned.

\section{b. Model setup}

The domain, on which the numerical simulations carried out in the present investigation were performed, is composed of an interior region, which includes the Rhine outflow area and of an outer region, in which a grid zooming (Roed and Cooper 1986) was implemented. The extension and orientation of the interior region are shown in Fig. A2, where the bathymetry used in the simulations, the boundaries along which the model was forced, and the area corresponding to the ERS SAR images presented in Figs. 2, 4, and 5 are also illustrated. Within the interior region, which covers an area of $80 \mathrm{~km} \times 50 \mathrm{~km}$, the spatial resolution is 500 
TABLE A1. Values of the model parameters used in the numerical simulations.

\begin{tabular}{lll}
\hline \hline Time step & $\Delta t$ & $20 \mathrm{~s}$ \\
Grid step & $\Delta x, \Delta y$ & $500 \mathrm{~m}$ \\
Coriolis parameter & $f$ & $1.14 \times 10^{-4} \mathrm{~s}^{-1}$ \\
Barotropic Rossby radius & $R_{D}$ & $123 \mathrm{~km}$ \\
Bottom friction coefficient & $\mathrm{c}_{d b}$ & $3.5 \times 10^{-3}$ \\
Interfacial friction coefficient & $c_{d i}$ & $1.0 \times 10^{-3}$ \\
Horizontal eddy diffusion & & \\
$\quad$ coefficient & $A_{h}$ & $50.0 \mathrm{~m}^{2} \mathrm{~s}^{-1}$ \\
Reduced gravity & $g^{\prime}$ & $0.15 \mathrm{~m} \mathrm{~s}^{-2}$ \\
\hline
\end{tabular}

$\mathrm{m}$ in both directions. This resolution was reduced in the outer region, which starts at $x=x^{*}$ and $y=y^{*}$ by successively increasing the grid step by a factor 1.05 in both directions. The model was forced by imposing in the upper water layer of its southeastern open boundary the river transport $U_{D}=Q / L$, where $Q$ represents the river discharge and $L=2 \Delta x$ the river width, and by imposing in the lower water layer of its southwestern open boundary a transport $U_{T R}$ which represents the sum of the tidal transport $U_{T}$ and of the residual transport $U_{R}$. While in each simulation the transports $U_{D}$ and $U_{R}$ remains unchanged as time elapses, $U_{T}$ varies in time as it represents a northeastward propagating barotropic, inviscid Kelvin wave, whose time evolution can be written as

$$
U_{T}=U_{T 0} \exp \left(-\frac{y}{R_{D}}\right) \cos \left(\sigma_{t} t\right) .
$$

Here $U_{T 0}$ denotes the (constant) amplitude of the tidal transport, $R_{D}$ the barotropic Rossby radius of deformation, and $\sigma_{t}=1.405 \times 10^{-4} \mathrm{~s}^{-1}$ the angular frequency of semidiurnal lunar tide.

In our model the mixing between marine and riverine water was neglected. In general this physical process plays an important role, especially in the frontal dynamics of the Rhine outflow region. However, as we restrict our investigation to the hydrodynamics of the near-mouth area where sea surface manifestations of the Rhine surface front are observed in ERS SAR images, we feel confident that this simplification does not affect significantly our results. The densities of the water masses in the two water layers were thus taken to be constant in our investigation. The chosen value of $g^{\prime}$ corresponds to a characteristic value for the two-layer stratification typical of the near-field Rhine outflow area (van Alphen et al. 1988). A complete list of the model parameters used in our simulations is given in Table A1.

\section{REFERENCES}

Alpers, W., 1985: Theory of radar imaging of internal waves. Nature, 314, 245-247.

— , and I. Hennings, 1984: A theory for the imaging mechanism of underwater bottom topography by real and synthetic aperture radar. J. Geophys. Res., 89, 10 529-10 546.

Askari, F., G. L. Geernaeft, W. C. Keller, and S. Raman, 1993: Radar imaging of thermal fronts. Int. J. Remote Sens., 14, 275-294.
Brandt, P., R. Romeiser, and A. Rubino, 1999: On the determination of characteristics of the interior ocean dynamics from radar signatures of oceanic internal solitary waves. J. Geophys. Res., 104, 30 039-30 046

da Silva, J. C. B., S. A. Ermakov, I. S. Robinson, D. R. G. Jeans, and S. V. Kijashko, 1998: Role of surface films in ERS SAR signatures of internal waves on the shelf, 1, Short-period internal waves. J. Geophys. Res., 103, 8009-8031.

de Kok, J. M., 1997: Baroclinic eddy formation in a Rhine plume model. J. Mar. Syst., 12, 35-52.

de Loor, G. P., 1981: The observation of tidal patterns, currents, and bathymetry with SLAR imagery of the sea. IEEE J. Oceanic Eng., OE-6 (4), 123-129.

de Ruijter, W. P. M., A. van der Giessen, and F. C. Groenendijk, 1992: Current and density structure in the Netherlands coastal zone. Dynamics and Exchange in Estuaries and the Coastal Zone, D. Prandle, Ed., Vol. 40, Coastal and Estuarine Studies, Amer. Geophys. Union, 529-550.

—, A. W. Visser, and W. G. Bos, 1997: The Rhine outflow: A prototypical pulsed discharge plume in a high energy shallow sea. J. Mar. Syst., 12, 263-276.

Ermakov, S. A., J. C. B. da Silva, and I. S. Robinson, 1998: Role of surface films in ERS SAR signatures of internal waves on the shelf. 2: Internal tidal waves. J. Geophys. Res., 103, 8033-8043.

Esenkov, O. E., and B. Cushman-Roisin, 1999: Modeling of twolayer eddies and coastal flows with a particle method. J. Geophys. Res., 104, 10 959-10980.

Evans, R. H., K. S. Baker, O. B. Brown, and R. C. Smith, 1985: Chronology of warm-core ring 82B. J. Geophys. Res., 90, 88038812 .

Fedorov, K. N., 1986: The physical nature and structure of oceanic fronts. Lecture Notes on Coastal and Estuarine Studies, Springer, $333 \mathrm{pp}$.

Friede, C. A., and Coauthors, 1991: Air-sea fluxes and surface turbulence around a sea surface temperature front. J. Geophys. Res., 96, 8593-8609.

Garvine, R. W., 1974a: Dynamics of small-scale oceanic fronts. $J$. Phys. Oceanogr., 4, 557-569.

- 1974b: Physical features of the Connecticut River outflow during high discharge. J. Geophys. Res., 79, 831-846.

_ 1977: Observation of the motion field of the Connecticut River plume. J. Geophys. Res., 82, 441-454.

1987: Estuary plumes and fronts in shelf waters: A layer model. J. Phys. Oceanogr., 17, 1877-1896.

_ 1996: Buoyant discharge on the inner continental shelf: A frontal model. J. Mar. Res., 54, 1-33.

- , and J. D. Monk, 1974: Frontal structure of a river plume. $J$. Geophys. Res., 79, 2251-2259.

Graber, H. C., D. R. Thompson, and R. E. Carande, 1996: Ocean surface features and currents measured with synthetic aperture radar interferometry and HF radar. J. Geophys. Res., 101, $25813-25832$.

Ingram, G., 1981: Characteristics of the Great Whale River plume. J. Geophys. Res., 86, 2017-2023.

Johannessen, J. A., R. A. Shuchman, O. M. Johannessen, K. L. Davidson, and D. R. Lyzenga, 1991: Synthetic aperture radar imaging of upper ocean circulation features and wind fronts. $J$. Geophys. Res., 96, $10411-10422$.

— — - G. Digranes, D. R. Lyzenga, C. Wackerman, O. M. Johannessen, and P. W. Vachon, 1996: Coastal ocean fronts and eddies imaged with ERS 1 synthetic aperture radar. J. Geophys. Res., 101, 6651-6667.

Joyce, T. M., 1984: Velocity and hydrographic structure of a Gulf Stream warm-core ring. J. Phys. Oceanogr., 14, 936-947.

Keller, W. C., V. Wismann, and W. Alpers, 1989: Tower-based measurements of the ocean C-band radar backscatter cross section. J. Geophys. Res., 94, 924-930.

Lewis, R. E., 1984: Circulation and mixing in estuary outflows. Contin. Shelf Res., 3, 201-214. 
Luketina, D. A., and J. Imberger, 1987: Characteristics of a surface buoyant jet. J. Geophys. Res., 92, 5435-5447.

Lyzenga, D. R., 1991: Interaction of short surface and electromagnetic waves with ocean fronts. J. Geophys. Res., 96, $10765-10772$.

—_, and J. R. Bennett, 1988: Full-spectrum modeling of synthetic aperture radar internal wave signatures. J. Geophys. Res., 93, 12 345-12 354.

McClimans, T. A., 1988: Estuarine fronts and river plumes. Physical Processes in Estuaries, J. Dronkers and W. van Leussen, Eds., Springer, 55-69.

McCreary, J. P., S. Zhang, and S. R. Shetye, 1997: Coastal circulation driven by river outflow in a variable-density $1 \frac{112}{2}$-layer model. $J$. Geophys. Res., 102, 15 535-15 554.

Miller, J., M. Goodberlet, and J. Zaitzeff, 1998: Airborne salinity mapper makes debut in coastal zone. Eos, Trans. Amer. Geophys. Union, 79, 176-177.

O'Donnell, J., 1990: The formation and fate of a river plume: A numerical model. J. Phys. Oceanogr., 20, 551-559.

_ 1993: Surface fronts in estuaries: A review. Estuaries, 16, 12 39 .

_ , and R. W. Garvine, 1983: A time-dependent, two-layer frontal model of buoyant plume dynamics. Tellus, 35, 73-80.

Otto, L., J. T. F. Zimmerman, G. K. Furnes, M. Mork, R. Saetre, an G. Becker, 1990: Review of the physical oceanography of the North Sea. Neth. J. Sea Res., 26, 161-238.

Pavia, E. G., and B. Cushman-Roisin, 1988: Modeling of oceanic fronts using a particle method. J. Geophys. Res., 93, 3554-3562.

_ , and —_, 1990: Merging of frontal eddies. J. Phys. Oceanogr., 20, 1886-1906.

_- and M. López, 1994: Long-term evolution of elongated warm eddies. J. Phys. Oceanogr., 24, 2201-2208.

Roed, L. P., and C. K. Cooper, 1986: Open boundary conditions in numerical ocean models. Advanced Physical Oceanographic $\mathrm{Nu}$ merical Modeling, J. J. O’Brien, Ed., D. Reidel Publishing, 411436.

Romeiser, R., and W. Alpers, 1997: An improved composite surface model for the radar backscattering cross section of the ocean surface model. 2: Model response to surface toughness variations and the radar imaging of underwater bottom topography. J. Geophys. Res., 102, 25 251-25 267.

_, A. Schmidt, and W. Alpers, 1994: A three-scale composite surface model for the ocean wave-radar modulation transfer function. J. Geophys. Res., 99, 9785-9801.
—_, W. Alpers, and V. Wismann, 1997: An improved composite surface model for the radar backscattering cross section of the ocean surface. 1: Theory of the model and optimization/ validation by scatterometer data. J. Geophys. Res., 102, $25237-25250$.

Rubino, A., K. Hessner, and P. Brandt, 2001: Decay of stable warmcore eddies in a layered frontal model. J. Phys. Oceanogr., 31 (12), in press.

Ruddick, K. G., L. Lahousse, and E. Donnay, 1994: Location of the Rhine plume front by airborne remote sensing. Contin. Shelf Res., 14, 325-332.

_ E. Deleersnijder, P. J. Luyten, and J. Ozer, 1995: Haline stratification in the Rhine-Meuse freshwater plume: A three-dimensional model sensitivity analysis. Contin. Shelf Res., 15, 15971630.

Simpson, J. H., and A. J. Souza, 1995: Semi-diurnal switching of stratification in the region of freshwater influence of the Rhine. J. Geophys. Res., 100, 7037-7044.

Sletten, M. A., G. O. Marmorino, T. F. Donato, D. J. McLaughlin, and E. Twarog, 1999: An airborne, real aperture radar study of the Chesapeake Bay outflow plume. J. Geophys. Res., 104, 12111222.

Stronach, J. A., 1977: Observations and modeling studies of the Fraser River plume. Ph.D. dissertation, University of British Columbia, Vancouver, British Columbia, Canada, 242 pp.

Sun, S., R. Bleck, and E. P. Chassignet, 1993: Layer outcropping in numerical models of stratified flows. J. Phys. Oceanogr., 23, $1877-1884$

Tyler, M. A., D. W. Coats, and D. M. Anderson, 1982: Encystment in a dynamic environment: Deposition of dinoflagellate cysts by a frontal convergence. Mar. Ecol. Prog. Ser., 7, 163-178.

van Alphen, J. S. L. J., W. P. M. de Ruijter, and J. C. Borst, 1988: Outflow and three-dimensional spreading of Rhine River water in the Netherlands coastal zone. Physical Processes in Estuaries, J. Dronkers and W. van Leussen, Eds., Springer, 70-92.

van der Giessen, A., W. P. M. de Ruijter, and J. C. Borst, 1990: Threedimensional current structure in the Dutch coastal zone. Neth. J. Sea Res., 25, 45-55.

Vogelzang, J., K. G. Ruddick, and J. B. Moens, 1997: On the signature of river outflow fronts in radar imagery. Int. J. Remote Sens., 18, 3479-3505.

Wright, L. D., and J. M. Coleman, 1971: Effluent expansion and interfacial mixing in the presence of a salt wedge, Mississippi River Delta. J. Geophys. Res., 76, 8649-8661. 